\title{
Removal of Safranin-0 from Aqueous Solution by Adsorption onto Kaolinite Clay
}

\author{
Kayode O. Adebowale1, Bamidele I. Olu-Owolabi1, Emmanuel C. Chigbundu1,2* \\ ${ }^{1}$ Department of Chemistry, Faculty of Sciences, University of Ibadan, Ibadan, Nigeria \\ ${ }^{2}$ Department of Chemical Sciences, Bells University of Technology, Ota, Nigeria \\ Email: emmachijy@yahoo.com
}

Received 7 August 2014; revised 29 August 2014; accepted 26 September 2014

Copyright (C) 2014 by authors and Scientific Research Publishing Inc.

This work is licensed under the Creative Commons Attribution International License (CC BY).

http://creativecommons.org/licenses/by/4.0/

c) (i) Open Access

\section{Abstract}

In this study, Natural Raw Kaolinite (NRK) clay was used as an adsorbent for the investigation of the adsorption kinetics, isotherms and thermodynamic parameters of a cationic dye Safranine-0, also known as Basic Red 2 (BR2) from aqueous solution. The effects of $\mathrm{pH}$, temperature, initial dye concentration and contact time on the adsorption capacity were evaluated and the adsorbent was characterized by XRD, BET and FTIR. The pseudo-first-order, pseudo-second-order kinetic models and the intraparticle diffusion model were used to describe the kinetic data and the rate constants were evaluated. The experimental data fitted very well with the pseudo-second-order kinetic model and also followed intraparticle diffusion model revealing that diffusion is not only the rate-controlling step. The Langmuir Freundlich and Dubinin-Radushkevic adsorption models were applied to describe the equilibrium isotherms and the isotherm constants were also determined. The Langmuir model agrees with experimental data well. The activation energy, change of Gibbs free energy, enthalpy and entropy of adsorption were also evaluated for the adsorption of BR2 onto NRK.

\section{Keywords}

Basic Red 2, Kaolinite, Adsorption, Kinetic, Thermodynamic, Surface Area

\section{Introduction}

Dyes and pigments represent one of the problematic pollutant groups in wastewaters. They are aromatic compounds with various functional groups and can be classified as anionic (direct, acid, and reactive dyes), cationic (basic dyes) and non-ionic (disperse dyes). They are introduced into wastewaters from various sources, ranging

\footnotetext{
*Corresponding author.
} 
from the dye manufacturing and textile finishing to rubber, leather, paper, plastics, and cosmetics industries. They can degrade to produce carcinogens and toxic products [1]. Most dyestuffs are designed to be resistant to environmental conditions like: light, effects of $\mathrm{pH}$ and microbial attack, etc. In addition, a very small amount of dye in water is highly visible due to their desirable aesthetic aspect [2] [3]. Thus, the removal of dyes from effluents could be considered as an important issue for risk assessment.

Several physical or chemical processes such as flocculation, precipitation, ion exchange, membrane filtration, electrochemical destruction, irradiation and ozonation are used to treat dye laden wastewaters [4] [5]. However, these conventional physicochemical and even biological treatment methods are ineffective, costly and mostly lead to generation of sludge or formation of byproducts that are undesirable [6] [7]. Among the physical methods available, adsorption process has proven to be highly effective in the removal of dyes from wastewater, especially if the adsorbent is inexpensive and readily available [8]. The use of clay minerals over commercially available adsorbents has become popular because they are low-cost, abundant, available, non-toxic and potential ion exchange materials. A few of clay minerals among which are sepiolite [9], kaolinite [10], montmorillonite [11], smectite [12], bentonite [13] and zeolite [14] have been investigated for removal harmful heavy metals and organic pollutant such as dyes.

Kaolinite is a 1:1 aluminosilicate consisting of a tetrahedral and an octahedral sheet. The silicate sheets $\left(\mathrm{Si}_{2} \mathrm{O}_{5}\right)$ bonded to aluminum oxide/hydroxide sheets $\left(\mathrm{Al}_{2}(\mathrm{OH})_{4}\right)$ called gibbsite are the successive 1:1 layers which are held together by hydrogen bonding of adjacent silica and alumina sheets. The permanent negative charge is produced because of isomorphic replacement of $\mathrm{Si}^{4+}$ by $\mathrm{Al}^{3+}$ in the silica tetrahedral sheet or of trivalent metal ions (such as $\mathrm{Al}^{3+}$ ) by divalent ions $\mathrm{Fe}^{2+}$ and $\mathrm{Mg}^{2+}$ in the alumina octahedral sheet, leaving a single negative charge for each substitution. As a result, both the alumina sheet surfaces and the crystal edges have a pH-dependent variable charge caused by broken bonds around the edges and exposed hydroxyl basal [15] [16]. Hence, the kaolinite surface is expected to have two kinds of binding sites that could interact with cations or basic dyes effectively.

Basic dyes are known as the brightest class of soluble dyes used in the textile industries for dyeing acrylic, nylon, silk and wood materials. Their tinctorial value is very high; less than $1 \mathrm{ppm}$ of the dye produces obvious coloration. Basic dye can also cause allergc dermatitis, skin irritation, cancer and mutations [17]-[20]. The present study has been designed to investigate a single stage adsorption of "Safranin-O", a cationic dye, also known as Basic Red 2 (BR2) (Figure 1) onto kaolinite clay mineral from Ubulu Ukwu in Delta State, Nigeria as a model of basic dyes. Of particular interest in this work was to investigate the equilibrium, thermodynamics and kinetics of BR2 removal by adsorption from aqueous solution. The different kinetic models employed to analyze the data for BR2 adsorption are pseudo-first-order, pseudo-second-order and intra-particle diffusion models. Experimental data were analyzed using the Langmuir, Freundlich and Dubinin-Radushkevic adsorption isotherms.

\section{Materials and Methods}

\subsection{Adsorbate and Adsorbent}

The adsorbate, Saffranin-O, a cationic diazo dye with the molecular characteristics shown in Table 1, was supplied by BDH chemicals Poole England certified for use as a chromosome stain in Flemming triple stain with a minimum dye content of $80 \%$. It is referred to as BR2 in this work. The chemical structure of BR2 is given in Figure 1. The adsorbent, kaolinite clay was obtained from Ubulu-Ukwu, Delta State, Nigeria.

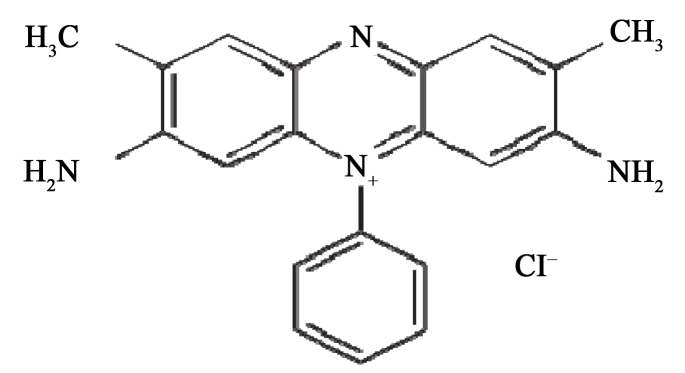

Figure 1. Molecular structure of Safranin-O (BR2). 
Table 1. Some molecular properties of Safranin-O (BR2).

\begin{tabular}{cc} 
Properties & BR2 \\
C.I. & 50,240 \\
Colour & Redish \\
Dye & $80 \%$ \\
Formula & $\mathrm{C}_{20} \mathrm{H}_{19} \mathrm{~N}_{4} \mathrm{Cl}$ \\
Molecular Weight (FW) & $350.85 \mathrm{~g}^{-\mathrm{mol}^{-1}}$ \\
pKa & 5.28 \\
Valence & +1 \\
$\lambda_{\max }$ & $520 \mathrm{~nm}$ \\
\hline
\end{tabular}

\subsection{Preparation of Adsorbent}

Stones and other non-clay particles were removed from the kaolinite clay sample by hand picking. It was then crushed and sieved through a meshed sieve to further remove the larger non-clay fractions. $100 \mathrm{~g}$ of the clay sample was dispersed in distilled deionized water and stirred continuously with a stirrer for $6 \mathrm{~h}$. Two layers were formed - a settlable heavier particulate layer and a colloidal suspension which is the kaolinite clay. The suspended layer was carefully and completely decanted after which the colloidal layer is recovered by centrifugation. It was further purified by using Renolds and Moores [21] method. This involves the stirring of the mixture in 30\% hydrogen peroxide solution till all effervescence has ceased. The mixture was kept standing overnight to allow any carbonaceous substance to be oxidized and with this treatment any organic substances remaining in the clay is removed. The supernatant was decanted and the kaolinite clay washed thoroughly with distilleddeionized water to remove traces of hydrogen peroxide. The peroxide free kaolinite clay was recovered by centrifugation and oven dried at $353 \mathrm{~K}$ to obtain the natural raw and untreated kaolinite clay sample (NRK). The dried sample was carefully crushed and sieved to produce the desired particle size. The X-Ray Diffraction (XRD) powder pattern of NRK was recorded on a Philips PW 3064/60 diffractometer (CuKa radiation; $\lambda=1.54060 \AA$ ) using a generator voltage of $40 \mathrm{kV}$ and a generator current of $40 \mathrm{~mA}$. A step size of $0.001^{\circ}(2 \theta)$ was used with a scan step time of 3.175 s per step. The infrared spectrum of NRK was obtained on a SHIMADZU Fourier Transform Infrared spectrometer under dry air prepared as $\mathrm{KBr}$ pellets. BET surface area and porosity measurements of clay sample were determined by quanta chrome quadrawin version 5.05 (Quantachrome, Germany). The samples were outgassed overnight $\left(20 \mathrm{~h}\right.$ ) at an outgassing temperature of $150.0^{\circ} \mathrm{C}$. The specific surface area was calculated on the basis of the BET equation installed in the machine.

\subsection{Preliminary Experiments}

Preliminary experiments demonstrated that equilibrium was established in less than $1 \mathrm{~h}$. A $2.50 \mathrm{~g}$ NRK was dispersed in $500 \mathrm{ml}$ dye solution of $100 \mathrm{mg} / \mathrm{L}$ concentration. One milliliters $(1 \mathrm{ml})$ of sample were withdrawn from the batch adsorption system at predetermined time intervals with the use of a micro-pipette (Dragon-Med Pipettor) and the supernatant was centrifuged at a speed of $2500 \mathrm{rpm}$ in $15 \mathrm{~min}$ to separate the used adsorbent from the remaining dye solution. The unadsorbed dye concentrations were determined from their absorbance characteristics in the UV-vis spectrophotometer [surgifriend SM7504UV/visible 911]. A linear correlation was established from the plot of BR2 dye concentration and the absorbance at $\lambda_{\max }=520 \mathrm{~nm}$, to give a correlation coefficient $r^{2}=0.994$. The adsorption capacity of the dye BR2 was calculated using the following relationships:

$$
\begin{gathered}
q t=\frac{\left(C_{O}-C_{t}\right) \times V}{W} \\
\%=\frac{\left(C_{O}-C_{t}\right) \times 100}{C_{O}}
\end{gathered}
$$


where $q_{t}(\mathrm{mg} / \mathrm{g})$ is the amount of BR2 dye adsorbed at contact time $t(\mathrm{~min}), C_{0}(\mathrm{mg} / \mathrm{L})$ is the initial dye concentration, $C_{t}(\mathrm{mg} / \mathrm{L})$ is the dye concentration at time $(t), V(\mathrm{~L})$ is the volume of the solution and $W$ (g) is the mass of clay in the solution.

\subsection{Adsorption Study}

\subsubsection{Effect of Initial $\mathrm{pH}$}

Effect of initial solution $\mathrm{pH}$ was investigated using various $\mathrm{pH}$ values in the range of 3 - 11 . The $\mathrm{pHs}$ of solutions were adjusted to the desired $\mathrm{pH}$ by adding drops of $0.1 \mathrm{M} \mathrm{NaOH}$ or $\mathrm{HCl}$. To $30 \mathrm{ml}$ of aqueous solution containing $100 \mathrm{mg} / \mathrm{L}$ BR2 dye, $0.5 \mathrm{~g}$ of NRK was added.

\subsubsection{Effect of Adsorbent Dose}

The effect of adsorbent dose variation on BR2 dye adsorption was studied by adding $0.05,0.10,0.15,0.20,0.30$, $0.45,0.70,0.90$ and $1.35 \mathrm{~g}$ of NRK to $30 \mathrm{ml}$ aqueous solution having an initial BR2 concentration of $300 \mathrm{mg} / \mathrm{L}$.

\subsubsection{Effect of Initial Dye Concentration}

The effect of the initial BR2 concentration variation was investigated by taking a fixed amount of the clay samples, $150 \mathrm{mg}$, and the concentration of dye adjusted from 20 to $300 \mathrm{mg} / \mathrm{L}$ at a volume of $30 \mathrm{ml}$.

\subsubsection{Effect of Temperature}

The effect of temperature was examined using $2.50 \mathrm{~g}$ adsorbents added to separate volumes of $500 \mathrm{ml}$ solutions containing BR2 concentrations of 50, 100 and $200 \mathrm{mg} / \mathrm{L}$ at different solution temperature varying between $20^{\circ} \mathrm{C}$ to $55^{\circ} \mathrm{C}$.

\subsection{Adsorption Kinetics}

The influence of contact time on the amount of BR2 adsorbed was investigated at a varied time interval at a constant adsorbent weight of $0.15 \mathrm{~g}$ and varied concentrations of 20,50,100, 150 and $170 \mathrm{mg} / \mathrm{L}$ of BR2 at a given temperature. Kinetic models, i.e. the pseudo-first order, the pseudo-second order and intraparticle diffusion models were considered for interpreting the experimental data obtained:

\subsubsection{Pseudo-First-Order Model}

The pseudo-first order kinetic model of Lagergren was used in order to estimate the adsorption capacity of the adsorbent [22]:

$$
\frac{\mathrm{d} q_{t}}{\mathrm{~d} t}=k_{1}\left(q_{e}-q_{t}\right)
$$

where $q_{e}$ and $q_{t}\left(\mathrm{mg} \cdot \mathrm{g}^{-1}\right)$ are the amounts of dye adsorbed onto the adsorbent at equilibrium and at various times $t$ ( $\mathrm{min}) ; k_{1}\left(\mathrm{~min}^{-1}\right)$, the rate constant of the first-order model for the adsorption process; integrating and applying the boundary conditions ( $t=0$ and $q_{t}=0$ to $t=t$ and $q_{t}=q_{t}$ ),

Equation (3) gives the form:

$$
\ln \left(q_{e}-q_{t}\right)=\ln \left(q_{e}\right)-k_{1} t
$$

The rate constant $k_{1}$ and $q_{e}$ were obtained from the slope and intercept of the linear plots of $\ln \left(q_{e}-q_{t}\right)$ against $t$, respectively.

\subsubsection{Pseudo-Second-Order Model}

The pseudo-second-order [23] reaction model is expressed as

$$
\frac{\mathrm{d} q_{t}}{\mathrm{~d} t}=k_{2}\left(q_{e}-q_{t}\right)^{2}
$$

where $k_{2}\left(\mathrm{~g} \cdot \mathrm{mg}^{-1} \cdot \mathrm{min}^{-1}\right)$ is the rate constant of the pseudo-second-order model for the adsorption process $q_{e}$ (mg/g) and $q_{t}(\mathrm{mg} / \mathrm{g})$ have the same definition as above for Equation (4). Integrating and applying boundary conditions ( $t=0$ and $q_{t}=0$ to $t=t$ and $q_{t}=q_{t}$ ), Equation (5) becomes; 


$$
q_{t}=\frac{t}{\left[\left(1 / k_{2} q_{e}^{2}\right)+t / q_{e}\right]}
$$

While the linear form is

$$
\frac{t}{q_{t}}=\frac{1}{\left(k_{2} q_{e}^{2}\right)}+\frac{t}{\left(q_{e}\right)}
$$

The rate constant $k_{2}\left(\mathrm{~g} \cdot \mathrm{mg}^{-1} \cdot \mathrm{min}^{-1}\right)$ and $q_{e}(\mathrm{mg} / \mathrm{g})$ were obtained from the intercept and slope of the linear plots of $t / q_{t}$ against $t$, respectively.

\subsubsection{The Intraparticle Diffusion}

The intraparticle diffusion equation was used accordingly which is written as

$$
q_{t}=k_{p} t^{0.5}+I
$$

where $q_{t}$ is same as defined as above, $k_{p}$, the intraparticle diffusion rate constant $\left(\mathrm{mg} \cdot \mathrm{g}^{-1} \cdot \mathrm{min}^{-0.5}\right)$ and $I$, give an idea about the thickness of the boundary layer, i.e., the larger the intercept the greater is the boundary layer effect [24]. To follow the intra-particle diffusion model, a plot of $q_{t}$ against $t^{0.5}$ should give a linear line where a slope is $k_{p}$ and intercept $I$.

\subsection{Adsorption Isotherms}

\subsubsection{Langmuir Isotherm}

The Langmuir isotherm has been widely applied to pollutants sorption processes. A basic assumption of the Langmuir theory is that the adsorption takes place at specific homogenous sites in the adsorbent. Moreover, when a site is occupied by a solute, no further adsorption can take place at this site [25]. The Langmuir adsorption isotherm can be written as follows

$$
q_{e}=\frac{K_{L} q_{\max } C_{e}}{1+K_{L} C_{e}}
$$

where $q_{e}\left(\mathrm{mg} \cdot \mathrm{g}^{-1}\right)$ is the amount of BR2 adsorbed onto clay samples at equilibrium, $q_{\max }\left(\mathrm{mg} \cdot \mathrm{g}^{-1}\right)$ is the theoretical monolayer capacity, $K_{L}(\mathrm{~L} / \mathrm{mol})$ is the Langmuir equilibrium constant related to the affinity of binding sites and energy of adsorption and $C_{e}\left(\mathrm{mg} \cdot \mathrm{L}^{-1}\right)$ is the equilibrium solution concentration. The linear form of the Langmuir isotherm equation is written as:

$$
\frac{C_{e}}{q_{e}}=\frac{C_{e}}{q_{\max }}+\frac{1}{K_{L} q_{\max }}
$$

The values of $q_{\max }$ and $K_{L}$ are evaluated from the intercept and the slope of the linear plot of experimental data of $C_{e} / q_{e}$ versus $C_{e}$ respectively.

\subsubsection{Equilibrium Parameter}

One of the essential characteristics of the Langmuir equation is that it could be expressed by dimensionless constant called equilibrium parameter $\left(R_{L}\right) . R_{L}$ is calculated using the following equation:

$$
R_{L}=1 /\left(1+K_{L} C_{O}\right)
$$

where $K_{L}\left(\mathrm{dm}^{3} \cdot \mathrm{mol}^{-1}\right)$ is the Langmuir constant and $C_{0}\left(\mathrm{mg} \cdot \mathrm{L}^{-1}\right)$ is the highest initial dye concentration.

The parameter indicates the type of isotherm to be; irreversible $\left(R_{L}=0\right)$, favorable $\left(0<R_{L}<1\right)$, linear $\left(R_{L}=1\right)$ or unfavorable $\left(R_{L}>1\right)$ [26].

\subsubsection{Freundlich Isotherm}

The Freundlich isotherm which is used to describe heterogeneous systems is expressed by the following empirical equation:

$$
q_{e}=K_{F} C^{1 / n}
$$




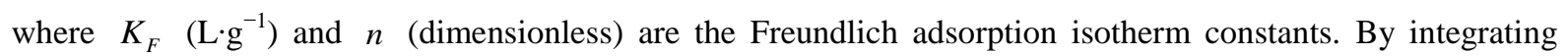
Equation (12) a linear form of the Freundlich equation is obtained;

$$
\ln q_{e}=\ln K_{F}+\frac{1}{n} \ln C_{e}
$$

\subsubsection{Dubinin-Radushkevic ( $D$ - $R$ ) Isotherm}

The adsorption data were analyzed using the linear form of the $D-R$ isotherm, [27] below:

$$
q_{e}=q_{\max } \exp \left(-B D\left[R T \ln \left(1+1 / C_{e}\right)\right]^{2}\right)
$$

where $q_{e}(\mathrm{mg} / \mathrm{g})$ is the amount of BR2 adsorbed, $q_{\max }(\mathrm{mg} / \mathrm{g})$ is the $D-R$ monolayer adsorption capacity, $T$ $(\mathrm{K})$ is the temperature and $C_{e}(\mathrm{mg} / \mathrm{L})$ is the equilibrium concentration of BR2 left in solution. Reducing Equation (14) and taking the logarithm of both side of the equation

$$
\ln q_{e}=\ln q_{\max }-B D \varepsilon^{2}
$$

$B D\left(\mathrm{~mol}^{2} \cdot \mathrm{kJ}^{-2}\right)$ is a constant related to sorption energy $E\left(\mathrm{KJ}^{\circ} \cdot \mathrm{mol}^{-1}\right)$, via the following relationship

$$
E=\frac{1}{(2 B D)^{0.5}}
$$

The mean adsorption energy $(E)$ is the Gibbs free energy change when $1 \mathrm{~mol}$ of the ion is transferred to the surface of the solid from infinity in the solution and $\varepsilon$ is the Polanyi potential, which is related to the equilibrium concentration as:

$$
\varepsilon=R T \ln \left(1+1 / C_{e}\right)
$$

The $B D$ and $q_{\max }$, Equation (15) are determined from slope and intercept of the plots of $\ln q_{e}$ versus $\varepsilon^{2}$ respectively.

\section{Result and Discussion}

\subsection{Characterization of Adsorbent}

The mineralogical composition of NRK determined from X-ray diffractogram shown in Figure 2. The clay was

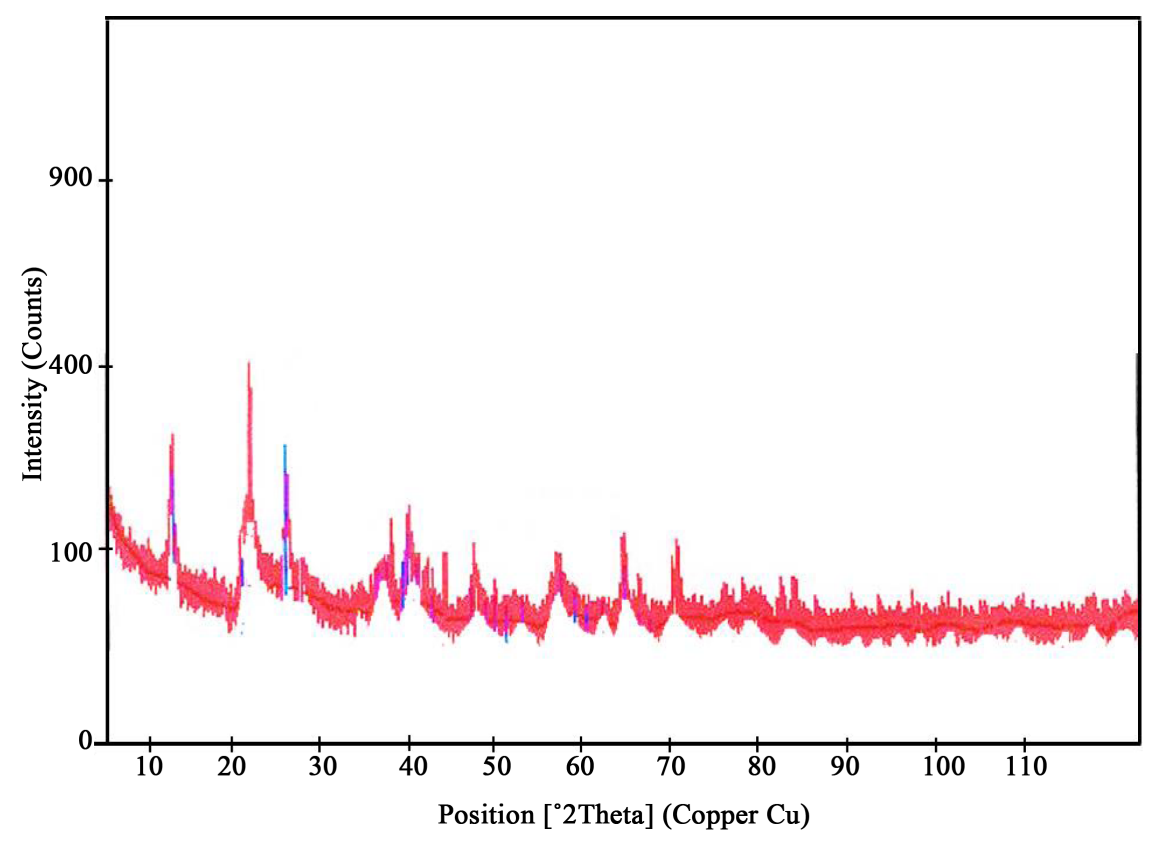

Figure 2. X-ray diffraction pattern of NRK. 
found to contain predominantly kaolinite and quartz minerals with some small amounts of illite, gibbsite and goethite (Table 2). The data suggests that the NRK consists mixture of kaolinite-illite clay mineral and this was inferred from the peaks with higher percentage relative intensities (Table 2). The percentages of elemental composition on the clay mineral suggests that it contains some little amount of nitrogenous compound (Table 3) and BET nitrogen adsorption method for NRK specific surface area and pore determination is shown in Table 4. Specific (BET) surface area is the total surface area of a solid that adsorbs a gas per unit weight of the solid. While the external surface area of a solid is the area of such solid which is attributed to the pores in other words it is the exposed surface of a solid residing almost exclusively inside the micropores for adsorption as such for a microporous solid/materials it is expected that the value for external surface area (ESA) be higher than the value for the specific surface area (SSA) (Table 4).

\subsection{FTIR Spectra Analysis of the Adsorbent}

Fourier transformed infrared spectra in the range $4000-500 \mathrm{~cm}^{-1}$ is shown in Figure 3. The band at $3620 \mathrm{~cm}^{-1}$ corresponds to the stretching vibration of the internal hydroxyl group of kaolinite while those at 3653 and 3697 $\mathrm{cm}^{-1}$ corresponds to the interlayer hydroxyl stretching mode [28]. While those at $3653 \mathrm{~cm}^{-1}, 3697 \mathrm{~cm}^{-1}$ corres ponds to interlayer hydroxyl stretching mode. The band at $2359 \mathrm{~cm}^{-1}$ is assigned to the-C-H stretching vibration

Table 2. XRD compositional analysis of NRK clay sample used in this study.

\begin{tabular}{ccc}
\hline Composition & d-spacing $[\AA]$ & Relative intensity (\%) \\
\hline Kaolinite & 7.166 & $14.32 \%$ \\
Kaolinite & 4.486 & $7.91 \%$ \\
Quartz & 4.263 & $27.63 \%$ \\
Kaolinite & 3.582 & $11.75 \%$ \\
Quartz + illite & 3.351 & $100.00 \%$ \\
Dolomite & 2.701 & $<5 \%$ \\
Quartz & 2.568 & $6 \%$ \\
Goethite & 2.504 & $<5 \%$ \\
Goethite & 2.461 & $<5 \%$ \\
Goethite + gibbsite & 2.343 & $<5 \%$ \\
Gibbsite & 2.242 & $<5 \%$ \\
Gibbsite & 2.133 & $<5 \%$ \\
Dickite & 1.983 & $<5 \%$ \\
\hline
\end{tabular}

Table 3. Elemental composition of purified NRK clay sample used in this study.

\begin{tabular}{cccccc}
\hline Clay & $\mathrm{H}$ & $\mathrm{S}$ & $\mathrm{N}$ & $\mathrm{C}$ & $\mathrm{C} / \mathrm{N}$ \\
\hline NRK & $1.147 \%$ & $0.258 \%$ & $1.33 \%$ & $0.12 \%$ & 0.0928 \\
\hline
\end{tabular}

Table 4. BET surface area and pore data for NRK.

\begin{tabular}{cc}
\hline Parameter & Value \\
\hline Specific surface area (SSA) & $27.8 \mathrm{~m}^{2} \cdot \mathrm{g}^{-1}$ \\
Total pore volume & $0.054 \mathrm{~cm}^{3} / \mathrm{g}$ \\
Average pore size & $2.67 \mathrm{~nm}$ \\
Average pore radius & $7.713 \AA$ \\
External surface area (ESA) & $34.61 \mathrm{~m}^{2} \cdot \mathrm{g}^{-1}$ \\
\hline
\end{tabular}




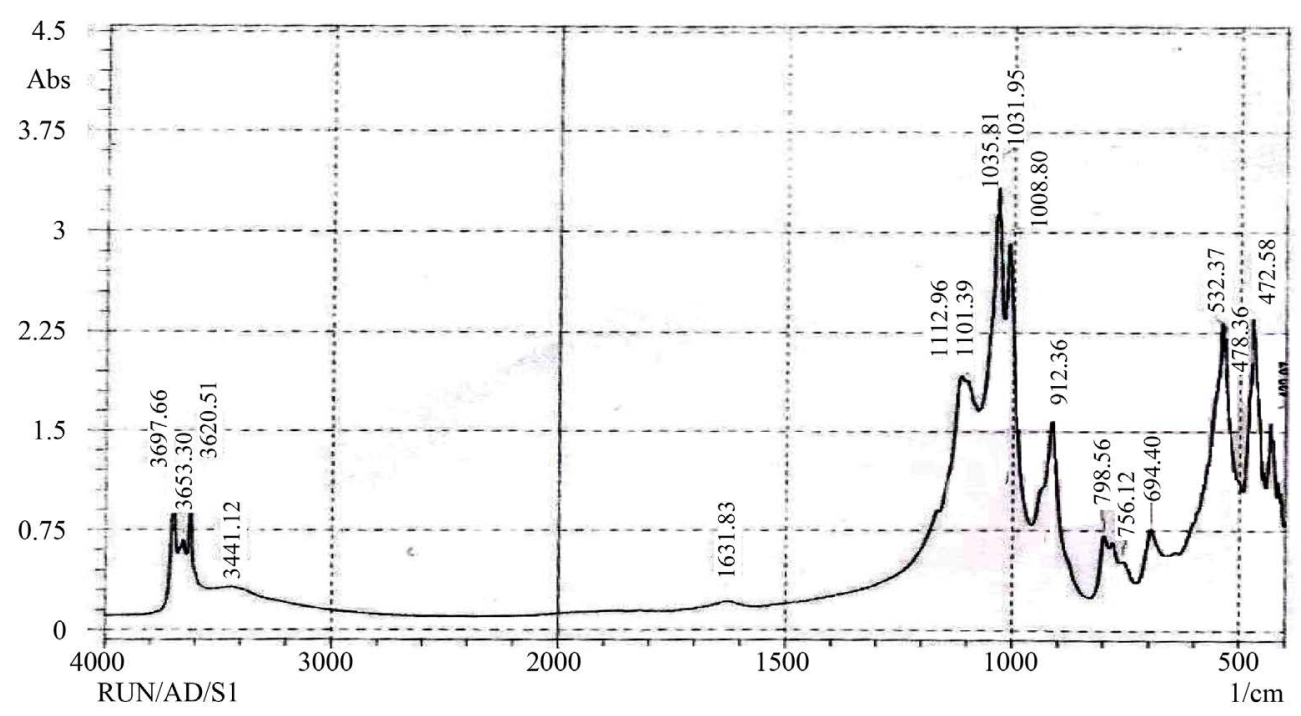

Figure 3. FTIR spectrum of purified NRK clay used for adsorption.

and the Si-O vibrational band can be observed at $1008 \mathrm{~cm}^{-1}$ and $1033 \mathrm{~cm}^{-1}$. The band at $1631.83 \mathrm{~cm}^{-1}$ is assigned to the $\mathrm{O}-\mathrm{H}$ stretching vibration of $\mathrm{H}_{2} \mathrm{O}$ of NRK [29].

\subsection{Effect of Initial pH}

Figure 4 shows the effect of $\mathrm{pH}$ on BR2 adsorption from aqueous solution onto NRK. The results showed that the percentage dye adsorption by the raw kaolinite increased significantly as $\mathrm{pH}$ increased. This $\mathrm{pH}$ effective-adsorption could have resulted from the fact that the $\mathrm{pH}$ of the dye solution can significantly affect the surface charge of NRK and the degree of ionization and speciation of BR2 molecule [30]. In addition, the negative charges on NRK which are mainly derived from the broken bonds around the edges and exposed hydroxyl basal strongly depend upon $\mathrm{pH}$ [31].

The increase in BR2 adsorption over the $\mathrm{pH}$ range may be related to two possible mechanisms: electrostatic interaction and chemical reaction between clay mineral and the dye molecules [32]. There is a significant increase in electrostatic attractions between positive charges of the cationic dye and the negative charges on the surface of NRK, thereby increasing dye adsorption. As the $\mathrm{pH}$ of the system increases, the number and strength of negatively charged sites on NRK increases and the number of positively charged sites on the surface decline which translates into a progressive increase in adsorption capacity of NRK. Similar observations have been made by other researchers [33]-[35].

\subsection{Effect of Adsorbent Dose Variation}

The percentage BR2 removal (\%) and amount adsorbed, $q_{e}$, per weight (g) NRK is shown in Figure 5. A close observation showed that an increase in adsorbent dose from $50 \mathrm{mg}$ to about $2.70 \mathrm{~g}$ resulted in a gradual and progressive decrease in adsorption capacity of NRK clay with respect to BR2 with a corresponding increase in the percentage dye adsorbed. This implied that the number of adsorption sites increased as adsorbent mass increases and this can be attributed to two possibilities; the increase in the adsorbent surface area and availability of more adsorption sites. However, the further increase in the amount of the adsorbent did not affect the uptake capacity significantly (Figure 5). Such a phenomenon was similar to those observed by Porkodi and Vasanth (2007) [36]; and Tahir and Rauf (2006) [37]. Consequently, the equilibrium adsorption capacity, $q_{e}$, decreased from 27.3 to $1.65 \mathrm{mg} / \mathrm{g}$, whereas, the percentage dye removal efficiency indicated that there was $99.1 \%$ increase in the dye removal as the adsorbent dose is increased from $50 \mathrm{mg}$ to $2.70 \mathrm{~g}$.

\subsection{Kinetic Studies}

The amount of BR2 removed at various initial dye concentrations by NRK as a function of time at constant adsorbent weight is graphically illustrated in Figure 6. From this figure, it was observed that the amount of BR2 


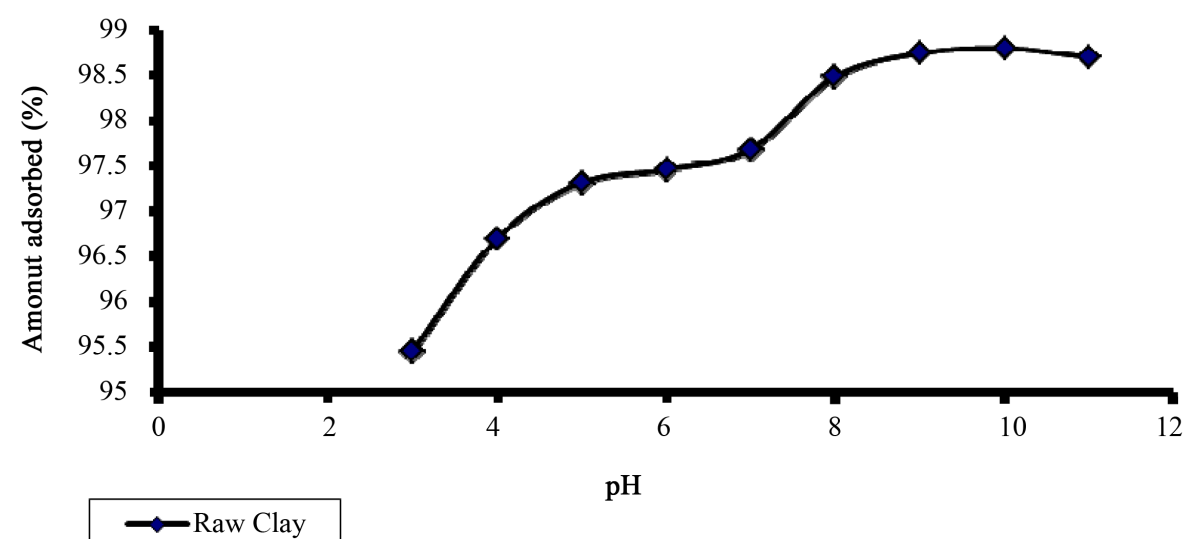

Figure 4. Effect of pH variation on the adsorption of BR2 onto NRK.

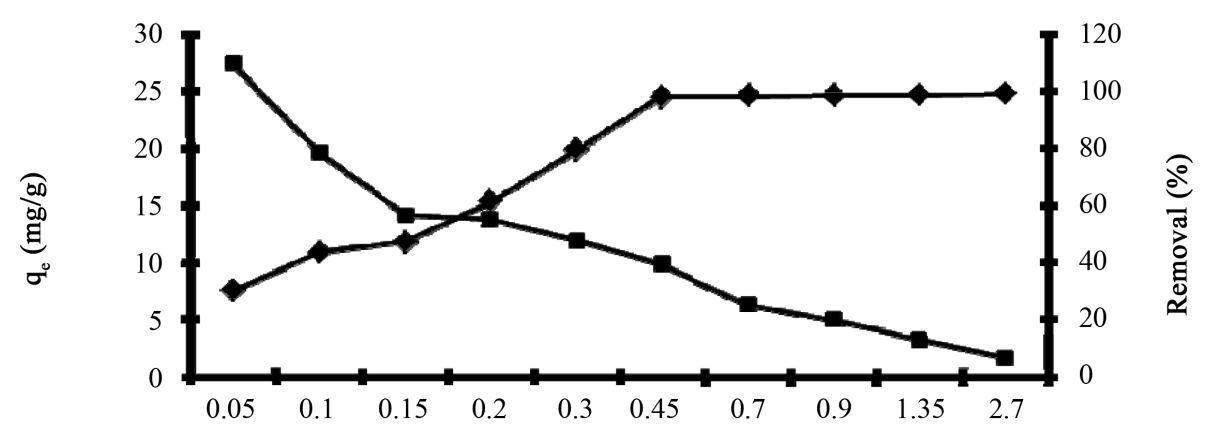

Adsorbent dose (g)

Figure 5. The variation of adsorbent dose at a constant BR2 dye concentration.

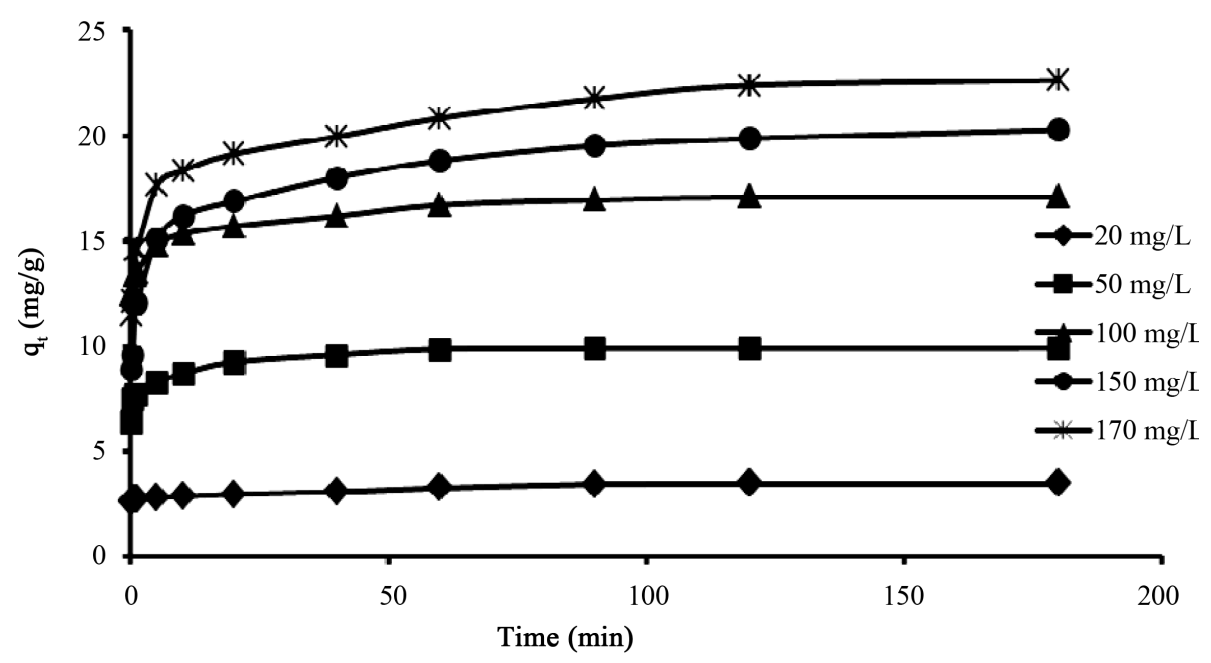

Figure 6. Kinetic curves of BR2 retention by NRK clay at different initial BR2 concentrations.

uptake, increased with time at all the initial dye concentrations. All the curves have similar characteristics, showing a fast adsorption, between time $t=0$ and $40 \mathrm{~min}$ after which, there is a slower adsorption profile until equilibrium was attained and the removal of BR2 by NRK clay became constant. For a contact time of $180 \mathrm{~min}$, percentage dye removal was $66.6 \%$ for $170 \mathrm{mg} / \mathrm{L}$ dye solution, $70.9 \%$ for $150 \mathrm{mg} / \mathrm{L}$ dye solution, $85.4 \%$ for 100 $\mathrm{mg} / \mathrm{L}$ dye solution, $88.4 \%$ for $50 \mathrm{mg} / \mathrm{L}$ dye solution and $88.8 \%$ for $20 \mathrm{mg} / \mathrm{L}$ dye solution. The sorption reaction at all initial dye concentrations was found to be rapid. 
For the kinetics study, two kinetic models were tested to explain the data presented in Figure 6, Viz; pseudo-first order, and pseudo-second order models. The lower values of $R^{2}$ and the difference between the experimental and calculated adsorption equilibrium values showed that the pseudo-first order model failed to describe the adsorption kinetics. Meanwhile, the agreement of experimental data with the calculated value is corroborated by the correlation coefficient $\left(R^{2}\right)$, meaning that pseudo-second order model (Figure 7) best describe the kinetics of the adsorption process (Table 5). The values of the rate constants $\left(k_{2}\right)$ were found to decrease from 0.189 to $0.023 \mathrm{mg} /(\mathrm{g} \cdot \mathrm{min})$ as the initial concentration increased from 20 to $170 \mathrm{mg} / \mathrm{L}$, an indication that the adsorption process is highly concentration dependent, which is consistent with earlier studies [38]-[40].

The kinetic data obtained was also analyzed by the intra-particle diffusion model. The curve (not shown) is multilinear which means that the intraparticle diffusion was not the only rate-limiting step and that there may be other steps involved in control of the rate of adsorption, all of which may be operating simultaneously [41]-[43]. This kind of multi-linearity in the shape of the intraparticle diffusion plot was also observed by Tarun et al. (2009) in the use of Saw dust and neem bark as low-cost natural biosorbent for adsorptive removal of Zn(II) and Cd(II) ions from aqueous solutions [44]. These phases in the intraparticle diffusion plot suggest that the adsorption process is complex such that the initial portion of the curved indicates a boundary layer effect; the second portion is then due to intraparticle diffusion while the third linear portion is likely due to chemical reaction [42].

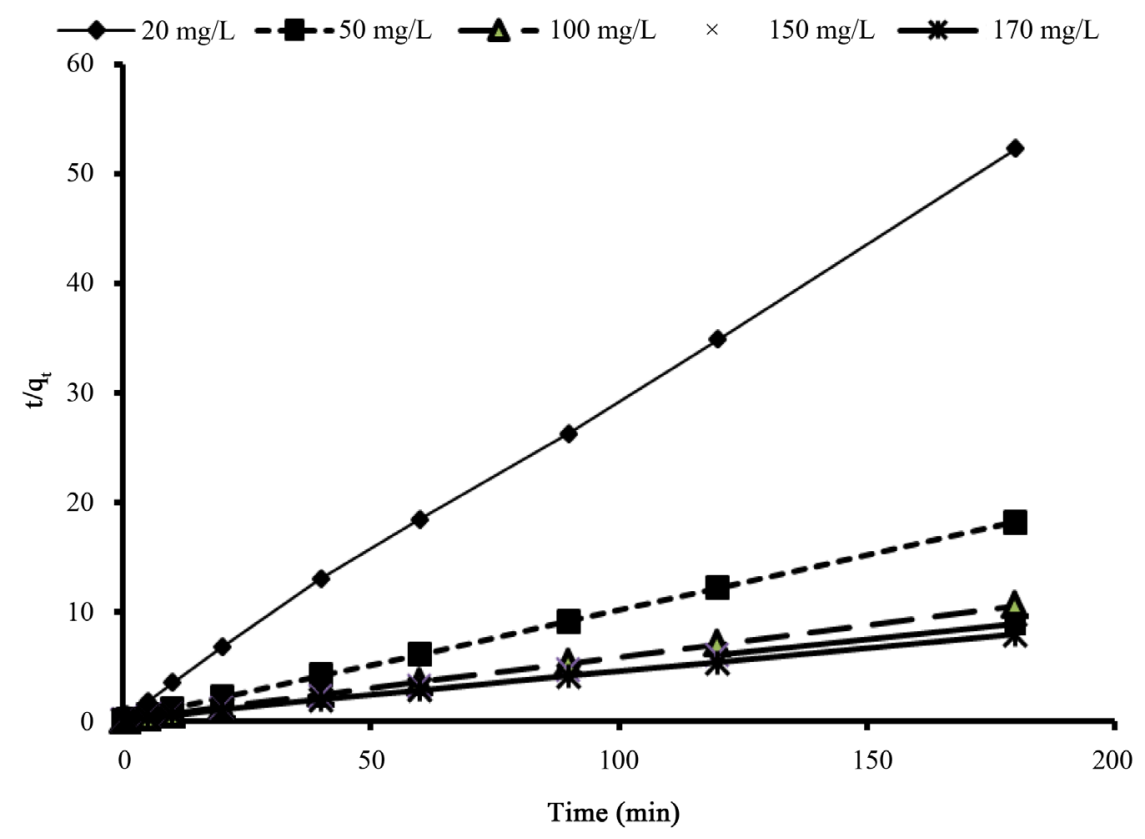

Figure 7. Pseudo-second order kinetic plot for adsorption of BR2 on NRK under different dye concentrations at temperature of $31^{\circ} \mathrm{C}$.

Table 5. Kinetics parameters for the removal of BR2 dye by NRK.

\begin{tabular}{cccccccccccc}
\hline & \multicolumn{3}{c}{ Pseudo-first order } & \multicolumn{3}{c}{ Pseudo-second order } & \multicolumn{3}{c}{ Intraparticle diffusion } \\
\hline $\begin{array}{c}{ }^{*} \mathrm{CO} \\
(\mathrm{mg} / \mathrm{L})\end{array}$ & $\begin{array}{c}\mathrm{qe}_{\text {exp }} \\
(\mathrm{mg} / \mathrm{g})\end{array}$ & $\begin{array}{c}\mathrm{qe}_{\mathrm{cal}} \\
(\mathrm{mg} / \mathrm{g})\end{array}$ & $\begin{array}{c}\mathrm{K}_{1} \\
\left(\mathrm{~min}^{-1}\right)\end{array}$ & $\mathrm{R}_{1}^{2}$ & $\begin{array}{c}\mathrm{qe}_{2 \mathrm{cal}} \\
(\mathrm{mg} / \mathrm{g})\end{array}$ & $\begin{array}{c}\mathrm{K}_{2} \\
(\mathrm{~g} / \mathrm{mg} / \mathrm{min})\end{array}$ & $\mathrm{R}_{2}^{2}$ & $\begin{array}{c}\mathrm{Kid} \\
\left(\mathrm{mg} \cdot \mathrm{g}^{-1} \cdot \mathrm{min}^{1 / 2}\right)\end{array}$ & $\begin{array}{c}\mathrm{I} \\
\left(\mathrm{mg} \cdot \mathrm{g}^{-1} \cdot \mathrm{min}^{1 / 2}\right)\end{array}$ & $\mathrm{R}_{\mathrm{i}}^{2}$ \\
20 & 3.44 & 0.824 & 0.0322 & 0.93 & 3.460 & 0.189 & 0.999 & 0.073 & 2.65 & 0.999 \\
50 & 9.89 & 2.000 & 0.0438 & 0.974 & 10.000 & 0.147 & 0.999 & 0.422 & 7.26 & 0.941 \\
100 & 17.07 & 4.246 & 0.0530 & 0.913 & 17.241 & 0.072 & 0.999 & 1.663 & 11.93 & 0.98 \\
150 & 20.28 & 10.864 & 0.0415 & 0.871 & 20.408 & 0.025 & 0.999 & 4.79 & 10.59 & 0.96 \\
170 & 22.64 & 11.803 & 0.0461 & 0.866 & 22.727 & 0.023 & 0.998 & 4.79 & 10.14 & 0.96 \\
\hline
\end{tabular}

${ }^{*}$ Initial BR2 dye concentration. 
The slope of the second portion of the plot is used in defining the intraparticle diffusion parameter, $\mathrm{k}_{\mathrm{id}}(\mathrm{mg} / \mathrm{g}$ $\min ^{1 / 2}$ ), as shown in Table 5 and this parameter increases as the concentration of the BR2 was increased.

On the other hand, the intercept (I), of the plot reflects the boundary layer effect. The larger the intercept, the greater the contribution of the surface sorption to the rate limiting step [45] this was also observed as the dye concentration increases (Table 5).

\subsection{Thermodynamic Parameters}

The thermodynamic parameters of the adsorption were determined using the following equations:

$$
\begin{aligned}
& \ln \left(k_{d}\right)=\frac{\Delta S_{\text {ads }}}{R}-\frac{\Delta H_{\text {ads }}}{R T} \\
& \Delta G_{\text {ads }}=\Delta H_{\text {ads }}-T \Delta S_{\text {ads }}
\end{aligned}
$$

where $k_{d}$ is the distribution coefficient at different temperatures $(293,303,313$, and $328 \mathrm{~K}$ ) and is equal to the ratio of the equilibrium amount adsorbed ( $C e_{A}$ in $\left.\mathrm{mg} / \mathrm{L}\right)$ to the equilibrium concentration $\left(C e_{S}\right.$ in $\left.\mathrm{mg} / \mathrm{l}\right)$ at different temperatures (i.e. $k_{d}=C e_{A} / C e_{S}$ ) and $R$ is the gas constant. The values of $\Delta H_{\text {ads }}$ and $\Delta S_{\text {ads }}$ for changes in enthalpy and entropy of reactions were obtained from the slope and intercept respectively of the linear plot of $\ln k_{d}$ versus $1 / T$ (Figure 8). Equation (19) was applied to calculate the standard change in Gibbs free energies, $\Delta G_{\text {ads }}$ at different temperatures.

The thermodynamic parameters are shown in Table 6. It is obvious that the adsorption of BR2 onto NRK is spontaneous and exothermic as the values for $\Delta G$ and $\Delta H$ are negative respectively and the entropy change $\left(\Delta S_{\text {ads }}\right)$ showed the disorderliness of the reacting dye particles during the interaction with surface of NRK.

\subsection{Equilibrium Studies}

The adsorption data were analyzed to see whether the isotherm obeyed the Langmuir [25], Freundlich [26] and Dubinin-Radushkevich $(D-R)$ [27] isotherm models equations. The non linear equations of each models were

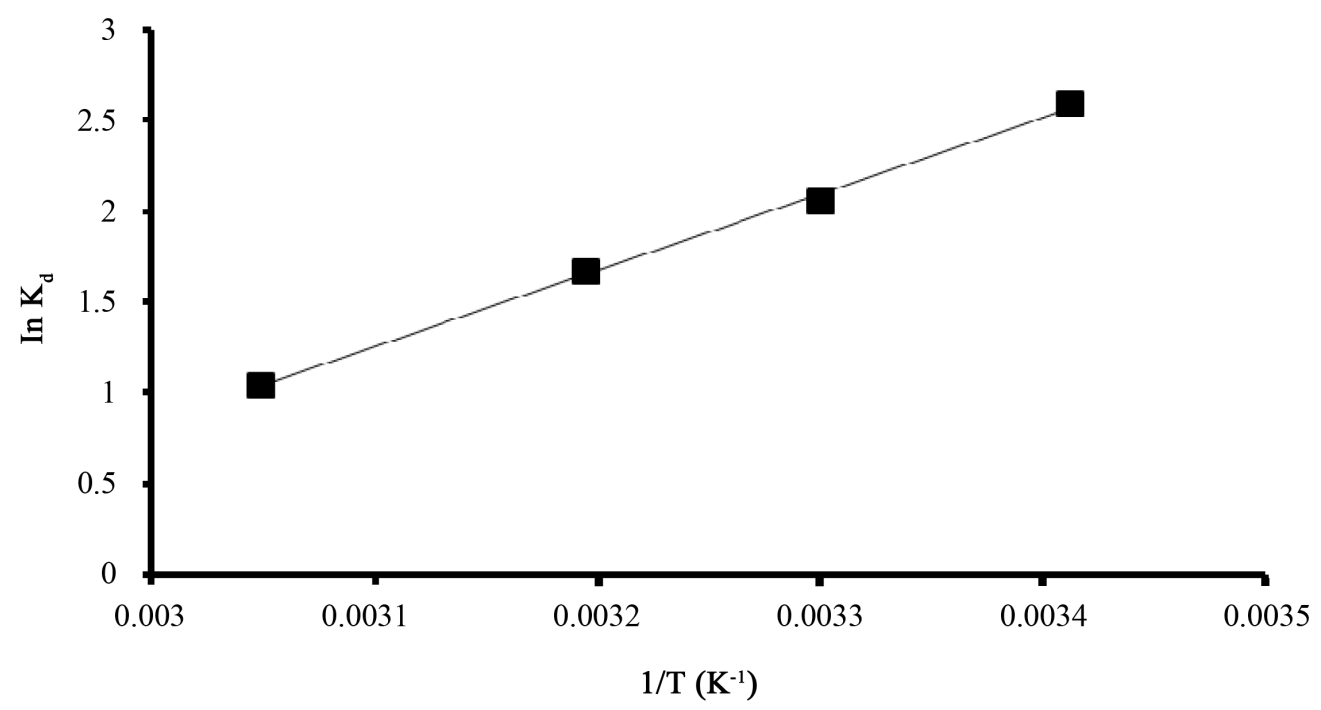

Figure 8. Van’t Hoff plot for the BR2 dye adsorption onto NRK clay at different temperature.

\begin{tabular}{|c|c|c|c|c|c|c|}
\hline \multirow[t]{2}{*}{ Clay } & \multicolumn{4}{|c|}{$\Delta \mathrm{G}(\mathrm{KJ} / \mathrm{mol})$} & \multirow[t]{2}{*}{$\Delta \mathrm{H}\left(\mathrm{KJ} \cdot \mathrm{mol}^{-1}\right)$} & \multirow[t]{2}{*}{$\Delta \mathrm{S}\left(\mathrm{KJ}^{-1} \cdot \mathrm{mol}^{-1}\right)$} \\
\hline & $293 \mathrm{~K}$ & $303 \mathrm{~K}$ & $313 \mathrm{~K}$ & $328 \mathrm{~K}$ & & \\
\hline NRK & -10.23 & -7.45 & -8.45 & -7.24 & -35.34 & -85.72 \\
\hline
\end{tabular}

Table 6. Thermodynamic parameters for BR2 adsorbed onto NRK clay sample. 
earlier respectively expressed in Equations (10), (13) and (15) above. The parameter for these isotherm models for the adsorption of BR2 onto NRK is listed in Table 7. The fit of the data for BR2 adsorption onto NRK suggests that the Langmuir isotherm model (Figure 9) gave better fittings than those of Freundlich but followed closely by $D-R$ models, as is obvious from a comparison of the correlation coefficient $\left(R^{2}\right)$ (Table 7). The effect of isotherm was also discussed with a view to predict whether an adsorption system is favorable or unfavorable. This is resolved by the use of the essential feature of the Langmuir isotherm expressed by means of " $R_{L}$ ”, Equation (11), a dimensionless constant referred to as separation factor or equilibrium parameter. The value of $R_{L}$ was calculated using Equation (11) and incorporated in Table 7. As shown, the $R_{L}$ value for BR2 onto NRK at $31^{\circ} \mathrm{C}$ is 0.3011 (Table 7), a value that lies between 0 and 1 , interprets that the adsorption

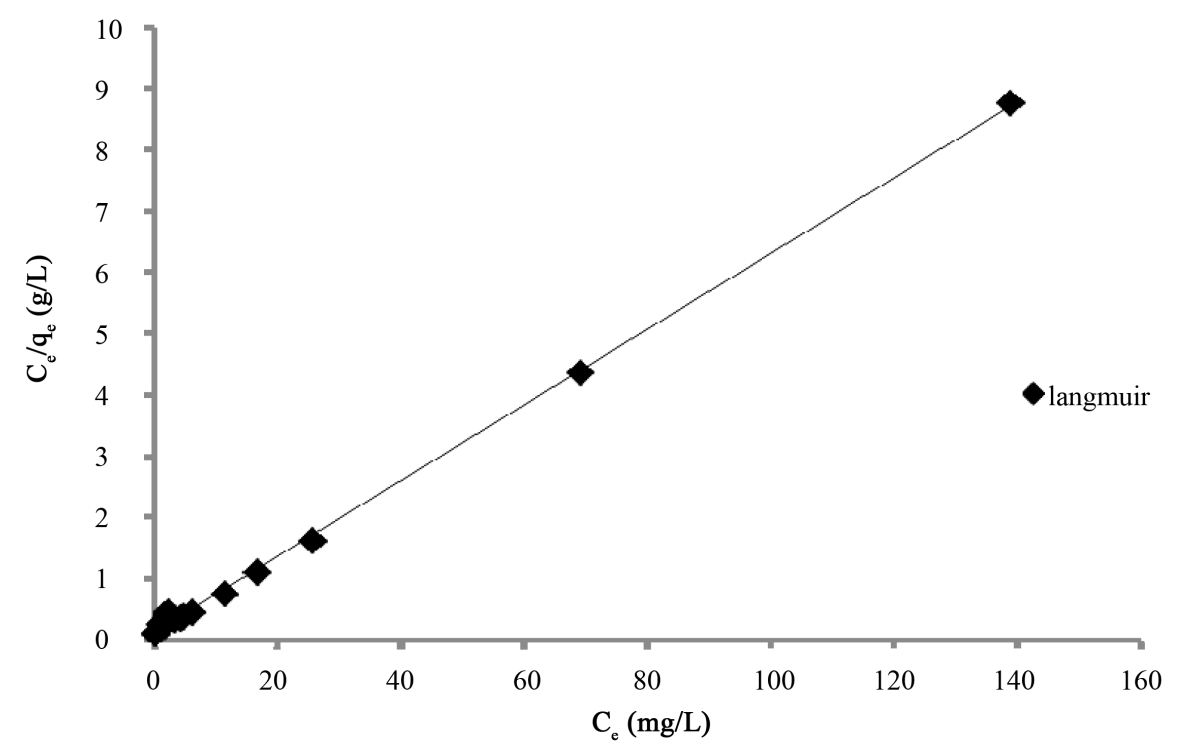

Figure 9. Langmuir isotherm model plot for BR2 adsorption onto NRK.

Table 7. Adsorption isotherm constants for BR2 adsorption onto NRK.

Langmuir

\begin{tabular}{|c|c|}
\hline $\mathrm{q}_{\max }(\mathrm{mg} / \mathrm{g})$ & 16.234 \\
\hline $\mathrm{K}_{\mathrm{L}}(\mathrm{L} / \mathrm{mg})$ & 0.431 \\
\hline $\mathrm{R}_{\mathrm{L}}$ & 0.3011 \\
\hline $\mathrm{R}_{\mathrm{L}}^{2}$ & 0.9987 \\
\hline \multicolumn{2}{|c|}{ Dubinin-Radushkevic } \\
\hline $\mathrm{q}_{\max }(\mathrm{mg} / \mathrm{g})$ & 16.071 \\
\hline $\mathrm{E}\left(\mathrm{KJ} \cdot \mathrm{mol}^{-1}\right)$ & 707.106 \\
\hline$\beta\left(\mathrm{mol}^{2} \cdot \mathrm{KJ}^{-2}\right)$ & $1.0 \times 10^{-6}$ \\
\hline $\mathrm{R}_{\mathrm{D}-\mathrm{R}}^{2}$ & 0.9932 \\
\hline \multicolumn{2}{|c|}{ Freundlich } \\
\hline $\mathrm{K}_{\mathrm{F}}(\mathrm{L} / \mathrm{mg})$ & 0.8966 \\
\hline $1 / \mathrm{n}$ & 0.6206 \\
\hline $\mathrm{R}_{\mathrm{F}}^{2}$ & 0.9125 \\
\hline
\end{tabular}


process is favorable [46].

In the energy parameter of $D-R$ isotherm models, the sorption energy $\left(\beta_{D}\right)$, and mean free energy $\left(E_{D}\right)$ value are estimated at $1.0 \times 10^{-0.6} \mathrm{~mol}^{2} / \mathrm{kJ}^{2}$ and $707.106 \mathrm{~kJ} / \mathrm{mol}$ respectively (Table 7). Meanwhile the parameter predicting the type of adsorption was evaluated as $E_{D}$ which is an indication of physisorption or chemisorptions or ion exchange etc. According to Atkins (1999) [47], physisorption is called a non specific adsorption which occur as a result of long range weak Van der Waals forces between adsorbates and adsorbents. The energy released when a particle is physisorbed is of the same magnitude as the enthalpy of condensation. The enthalpy of physisorption was however measured in the region of less than $20 \mathrm{~kJ} / \mathrm{Mol}$ [47]. He also argued that chemisorption is a specific adsorption and limited to monolayer coverage of the substrate [47]. Here, a covalent bond is formed between the adsorbate and adsorbent. In this study, the estimated value for mean free energy is higher than $20 \mathrm{~kJ} / \mathrm{Mol}$ and moreover surface coverage in this experiment fitted best into the Langmuir Isotherm (sorption on homogeneous surface). Hence, adsorption is restricted to monolayer coverage as purposed for chemisorption. A comparison of previous adsorption capacities of BR2 adsorbed onto various adsorbents is presented in Table 8. It can be seen that NRK in this study has a lower adsorption capacity compared to other adsorbents.

\section{Conclusions}

This study investigated the interaction of a cationic dye with the partially negatively charged surface of natural kaolinite namely BR2 (Safranin-O) onto NRK. At the end, it was found that, more than 90 percent of dye removal was achieved by using $150 \mathrm{mg}$ of the adsorbent for an initial dye concentration of $100 \mathrm{mg} \cdot \mathrm{L}^{-1}$.

Due to strong electrostatic interaction between BR2 and NRK, the pseudo-second-order very well predicted the behaviour of adsorption at different dye concentrations and the intraparticle diffusion models (up to $10 \mathrm{~min}$ ) played a significant role, but it was not the main rate-determining step during the adsorption.

The experimental data best fit with the Langmuir isotherm showing that the surface of the kaolinite particle in the removal of BR2 has homogeneous distribution of active sites within the clay, equal energy of adsorption and equivalent in nature.

The enthalpy change $\left(\Delta H^{0}\right)$ for the adsorption process was $-35.34 \mathrm{~kJ} \cdot \mathrm{mol}^{-1}$, an exothermic reaction, which did not indicate a strong chemical interaction between the adsorbed dye molecules and NRK. The $\Delta G^{0}$ values were negative therefore the adsorption was spontaneous and the negative value of $\Delta S^{0}$ suggested a decreased randomness at the solid/solution interface.

\section{Acknowledgements}

The authors wish to acknowledge Prof. Jens Weber of the Max Planck Institute of Colloids and Interfaces,

Table 8. Reported maximum adsorption capacities in the literature for Safranin-O adsorbed onto different adsorbents.

\begin{tabular}{ccc}
\hline & Adsorption & \\
\hline Adsorbents & Capacities $\left(\mathrm{Q}_{\max }\right)$ & References \\
\hline K. fragilis & $138.20 \mathrm{mg} / \mathrm{g}$ & Ivo Safarik, 1995 \\
Activated Carbon & $132.5-265 \mathrm{mg} / \mathrm{g}$ & Ivo Safarik et al., 1997 \\
Activated Carbon & $131.58 \mathrm{mg} / \mathrm{g}$ & Gokturk and Kalue, 2008 \\
$\begin{array}{c}\text { Mango Seed } \\
\text { Integuments (Untreated) } \\
\text { Mango Seed } \\
\text { Integuments (Treated) } \\
\text { Rice Husk }\end{array}$ & $34.48 \mathrm{mg} / \mathrm{g}$ & Mohamad et al., 2012 \\
Palygorskite Clay & $43.47 \mathrm{mg} / \mathrm{g}$ & Mohamad et al., 2012 \\
Kaolinite (NRK) Clay & $105.9 \mathrm{mg} / \mathrm{g}$ & Papita and Rahul, 2012 \\
\hline
\end{tabular}


Potsdam, Germany for running the BET analysis and Dr. E. I. Unuabonah, for the successful completion of this research.

\section{References}

[1] Chiou, M.-S. and Li, H.-Y. (2003) Adsorption Behavior of Reactive Dyes in Aqueous Solution on Chemical CrossLinked Chitosan Beads. Chemosphere, 50, 1095-1105. http://dx.doi.org/10.1016/S0045-6535(02)00636-7

[2] Ozcan, A.S., Erdem, B. and Ozcan, A. (2005) Adsorption of Acid Blue 193 from Aqueous Solutions onto BTMABentonite. Colloids and Surfaces A: Physicochemical and Engineering Aspects, 266, 73-81. http://dx.doi.org/10.1016/j.colsurfa.2005.06.001

[3] Sun, Q.Y. and Yang, L.Z. (2003) The Adsorption of Basic Dyes from Aqueous Solution on Modified Peat-Resin Particle. Water Research, 37, 1535-1544. http://dx.doi.org/10.1016/S0043-1354(02)00520-1

[4] Ozacar, M. and Sengil, I.A. (2002) Adsorption of Acid Dyes from Aqueous Solutions by Calcined Alunite and Granular Activated Carbon. Adsorption, 8, 301-308. http://dx.doi.org/10.1023/A:1021585413857

[5] Ozacar, M. and Sengil, I.A. (2003) Adsorption of Reactive Dyes on Calcined Alunite from Aqueous Solutions. Journal of Hazardous Materials, B98, 211-224. http://dx.doi.org/10.1016/S0304-3894(02)00358-8

[6] Robinson, T., McMullan, G., Marchant, R. and Nigam, P. (2001) Remediation of Dyes in Textile Effluent: A Critical Review on Current Treatment Technologies with a Proposed Alternative. Bioresource Technology, 77, 247-255. http://dx.doi.org/10.1016/S0960-8524(00)00080-8

[7] Malik, P.K. (2003) Use of Activated Carbons Prepared from Sawdust and Rice-Husk for Adsorption of Acid Dyes: A Case Study of Acid Yellow 36. Dyes Pigments, 56, 239-249. http://dx.doi.org/10.1016/S0143-7208(02)00159-6

[8] Al-Futaisi, A., Jamrah, A. and Al-Hanai, R. (2007) Aspects of Cationic Dye Molecule Adsorption to Palygorskite. Desalination, 214, 327-342. http://dx.doi.org/10.1016/j.desal.2006.10.024

[9] Eren, E. and Afsin, B. (2007) Investigation of a Basic Dye Adsorption from Aqueous Solution onto Raw and PreTreated Sepiolite Surfaces. Dyes Pigments, 73, 162-167. http://dx.doi.org/10.1016/j.dyepig.2005.11.004

[10] Yuvuz, O. Altunkayank, Y. and Guzel, F. (2003) Removal of Copper, Nickel, Cobalt and Manganese from Aqueous Solution by Kaolinite. Water Research, 37, 948-952. http://dx.doi.org/10.1016/S0043-1354(02)00409-8

[11] Tertre, E., Berger, G., Castet, S., Loubet, M. and Giffaut, E. (2005) Experimental Sorption of $\mathrm{Ni}^{2+}, \mathrm{Cs}^{+}$and $\mathrm{Ln}^{3+}$ onto a Montmorillonite up to $150^{\circ} \mathrm{C}$. Geochimica et Cosmochimica Acta, 69, 4937-4948. http://dx.doi.org/10.1016/j.gca.2005.04.024

[12] Coppin, F., Berger, G., Bauer, A., Castet, S. and Loubet, M. (2002) Sorption of Lanthanides on Smectite and Kaolinite. Chemical Geology, 182, 57-68. http://dx.doi.org/10.1016/S0009-2541(01)00283-2

[13] Yıldız, N., Gönülşena, R., Koyuncu, H. and Çalımlıa, A. (2005) Adsorption of Benzoic Acid and Hydroquinone by Organically Modified Bentonites. Colloids and Surfaces A: Physicochemical and Engineering Aspects, 260, 87-94. http://dx.doi.org/10.1016/j.colsurfa.2005.03.006

[14] Wang, S. and Ariyanto, E. (2007) Competitive Adsorption of Malachite Green and Pb Ions on Natural Zeolite. Journal of Colloid and Interface Science, 314, 25-31. http://dx.doi.org/10.1016/j.jcis.2007.05.032

[15] Ghosh, D. and Bhattacharyya, K.G. (2002) Adsorption of Methylene Blue on Kaolinite. Applied Clay Science, 20, 295300. http://dx.doi.org/10.1016/S0169-1317(01)00081-3

[16] Ramasamy, V. and Anandalakshmi, K. (2008) The Determination of Kaolinite Clay Content in Limestones of Western Tamil Nadu by Methylene Blue Adsorption Using UV-Vis Spectroscopy. Spectrochimica Acta Part A: Molecular and Biomolecular Spectroscopy, 70, 25-29. http://dx.doi.org/10.1016/j.saa.2007.07.008

[17] Robinson, T., McMullan, G., Marchant, R. and Nigam, P. (2001) Remediation of Dyes in Textile Effluent: A Critical Review on Current Treatment Technologies with a Proposed Alternative. Bioresource Technology, 77, 247-255. http://dx.doi.org/10.1016/S0960-8524(00)00080-8

[18] Gokturk, S. and Kalu, S. (2008) Removal of Selected Organic Compounds in Aqueous Solution by Activated Carbon. Journal of Environmental Sciences and Technology, 1, 111-123. http://dx.doi.org/10.3923/jest.2008.111.123

[19] Malekbala, M.R., Soltani, S.M., Yazdi, S.K. and Hosseini, S. (2012) Equilibrium and Kinetic Studies of Safranin Adsorption on Alkali-Treated Seed Integuments. International Journal of Chemical Engineering and Applications, 3, 160166.

[20] Šafařík, I., Nymburská, K. and Šafaříková, M. (1997) Adsorption of Water-Soluble Organic Dyes on Magnetic Charcoal. Journal of Chemical Technology and Biotechnology, 69, 1-4.

[21] Moore, D.M. and Reynolds Jr., R.C. (1989) X-Ray Diffraction and the Identification and Analysis of Clay Minerals. Oxford University Press, Oxford, 179-201. 
[22] Gürses, A., Doğarc, C., Yalçına, M., Açıkyıldız, M., Bayrak, R. and Karaca, S. (2006) The Adsorption Kinetics of the Cationic Dye, Methylene Blue, Onto Clay. Journal of Hazardous Material, 131, 217-228. http://dx.doi.org/10.1016/j.jhazmat.2005.09.036

[23] Önal, Y., Akmil-Başar, C. and Sarici-Özdemir, Ç. (2007) Investigation Kinetics Mechanisms of Adsorption Malachite Green onto Activated Carbon. Journal of Hazardous Materials, 146, 194-203. http://dx.doi.org/10.1016/j.jhazmat.2006.12.006

[24] Mall, I.D., Srivastava, V.C., Agarwal, N.K. and Mishra, I.M. (2005) Removal of Congo Red from Aqueous Solution by Bagasse Fly Ash and Activated Carbon: Kinetic Study and Equilibrium Isotherm Analyses. Chemosphere, 61, 492501. http://dx.doi.org/10.1016/j.chemosphere.2005.03.065

[25] Langmuir, I. (1918) The Adsorption of Gases on Plane Surface of Glass, Mica and Platinum. Journal of the American Chemical Society, 40, 1361-1403.

[26] Sivaraj, R., Namasivayam, C. and Kadirvelu, K. (2001) Orange Peel as an Adsorbent in the Removal of Acid Violet 17 (Acid Dye) from Aqueous Solutions. Waste Management, 21, 105-110. http://dx.doi.org/10.1016/S0956-053X(00)00076-3

[27] Dubinin, M.M. and Radushkevich, L.V. (1947) The Equation of the Characteristic Curve of Activated Charcoal. Proceedings of the Academy of Sciences, Physical Chemistry Section, 55, 331.

[28] Patel, H.A., Somani, R.S., Bajaj, H.C. and Jasra, R.V. (2007) Preparation and Characterization of Phosphonium Montmorillonite with Enhanced Thermal Stability. Applied Clay Science, 35, 194-200. http://dx.doi.org/10.1016/j.clay.2006.09.012

[29] Unuabonah, E.I., Olu-Owolabi, B.I., Adebowale, K.O. and Yang, L.Z. (2008) Removal of Lead and Cadmium from Aqueous Solution by Polyvinyl Alcohol-Modified Kaolinite Clay: A Novel Nano-Clay Adsorbent. Adsorption Science and Technology, 26, 383-405. http://dx.doi.org/10.1260/0263-6174.26.6.383

[30] Özcan, A.S., Erdem, B. and Özcan, A. (2005) Adsorption of Acid Blue 193 from Aqueous Solutions onto BTMA-Bentonite. Colloids and Surfaces A: Physicochemical and Engineering Aspects, 266, 73-81. http://dx.doi.org/10.1016/j.colsurfa.2005.06.001

[31] Quek, S.Y. and Al-Duri, B. (2007) Application of Film-Pore Diffusion Model for the Adsorption of Metal Ions on Coir in a Fixed-Bed Column. Chemical Engineering and Processing: Process Intensification, 46, 477-485. http://dx.doi.org/10.1016/j.cep.2006.06.019

[32] Özcan, A.S., Erdem, B. and Özcan, A. (2004) Adsorption of Acid Blue 193 from Aqueous Solutions onto Na-Bentonite and DTMA-Bentonite. Journal of Colloid and Interface Science, 280, 44-54. http://dx.doi.org/10.1016/j.jcis.2004.07.035

[33] Karim, A.B., Mounir, B., Hachkar, M., Bakasse, M. and Yaacoubi, A. (2009) Removal of Basic Red 46 Dye from Aqueous Solution by Adsorption onto Moroccan Clay. Journal of Hazardous Materials, 168, 304-309. http://dx.doi.org/10.1016/j.jhazmat.2009.02.028

[34] Janoš, P., Buchtová, H. and Rýznarová, M. (2003) Sorption of Dyes from Aqueous Solutions onto Fly Ash. Water Research, 37, 4938-4944. http://dx.doi.org/10.1016/j.watres.2003.08.011

[35] Khraisheh, M.A.M., Al-Ghouti, M.A., Allen, S.J. and Ahmad, M.N. (2005) Effect of OH and Silanol Groups in the Removal of Dyes from Aqueous Solution Using Diatomite. Water Research, 39, 922-932. http://dx.doi.org/10.1016/j.watres.2004.12.008

[36] Porkodi, K. and Kumar, K.V. (2007) Equilibrium, Kinetics and Mechanism Modeling and Simulation of Basic and Acid Dyes Sorption onto Jute Fiber Carbon: Eosin Yellow, Malachite Green and Crystal Violet Single Component Systems. Journal of Hazardous Materials, 143, 311-327. http://dx.doi.org/10.1016/j.jhazmat.2006.09.029

[37] Tahir, S.S. and Rauf, N. (2006) Removal of Cationic Dye from Aqueous Solutions by Adsorption onto Bentonite Clay. Chemosphere, 63, 1842-1848. http://dx.doi.org/10.1016/j.chemosphere.2005.10.033

[38] Özcan, A., Öncü, E.M. and Özcan, A.S. (2006) Adsorption of Acid Blue 193 from Aqueous Solutions onto DEDMASepiolite. Journal of Hazardous Materials, 129, 244-252.

[39] Tsai, W.T., Hsu, H.C., Su, T.Y., Lin, K.Y., Lin, C.M. and Dai, T.H. (2007) The Adsorption of Cationic Dye from Aqueous Solution onto Acid-Activated Andesite. Journal of Hazardous Materials, 147, 1056-1062. http://dx.doi.org/10.1016/j.jhazmat.2007.01.141

[40] Ofomaja, A.E. (2007) Kinetics and Mechanism of Methylene Blue Sorption onto Palm Kernel Fibre. Process Biochemistry, 42, 16-24. http://dx.doi.org/10.1016/j.procbio.2006.07.005

[41] Kannan, N. and Sundaram, M.M. (2001) Kinetics and Mechanism of Removal of Methylene Blue by Adsorption on Various Carbons-A Comparative Study. Dyes and Pigments, 51, 25-40. http://dx.doi.org/10.1016/S0143-7208(01)00056-0

[42] Bhattacharyya, K.G. and Sharma, A. (2004) Azadirachta indica Leaf Powder as an Effective Biosorbent for Dyes: A 
Case Study with Aqueous Congo Red Solutions. Journal of Environmental Management, 71, 217-229. http://dx.doi.org/10.1016/j.jenvman.2004.03.002

[43] Chen, J.P., Wu, S. and Chong, K.H. (2003) Surface Modification of a Granular Activated Carbon by Citric Acid for Enhancement of Copper Adsorption. Carbon, 41, 1979-1986. http://dx.doi.org/10.1016/S0008-6223(03)00197-0

[44] Naiya, T.K., Chowdhury, P., Bhattacharya, A.K. and Das, S.K. (2009) Saw Dust and Neem Bark as Low-Cost Natural Biosorbent for Adsorptive Removal of $\mathrm{Zn}(\mathrm{II})$ and Cd(II) Ions from Aqueous Solutions. Chemical Engineering Journal, 148, 68-79. http://dx.doi.org/10.1016/j.cej.2008.08.002

[45] Ozacar, M. and Sengil, I.A. (2005) Adsorption of Metal Complex Dyes from Aqueous Solutions by Pine Sawdust. Bioresource Technology, 96, 791-795. http://dx.doi.org/10.1016/j.biortech.2004.07.011

[46] Ahmad, A.A., Hameed, B.H. and Aziz, N. (2007) Adsorption of Direct Dye on Palm Ash: Kinetic and Equilibrium Modeling. Journal of Hazardous Materials, 141, 70-76. http://dx.doi.org/10.1016/j.jhazmat.2006.06.094

[47] Atkins, P. (1999) Physical Chemistry. 6th Edition, Oxford University Press, London, 857-864.

\section{Abbreviations/Nomenclatures}

BR2: Basic Red 2.

$B D$ : A constant related to sorption energy $\mathrm{E}\left(\mathrm{mol}^{2} \cdot \mathrm{kJ}^{-2}\right)$.

$\mathrm{Ce}_{\mathrm{A}}$ : Amount adsorbed at equilibrium $\left(\mathrm{mg} \cdot \mathrm{L}^{-1}\right)$.

$\mathrm{Ce}_{S}$ : Dye equilibrium concentration in solution $\left(\mathrm{mg} \cdot \mathrm{L}^{-1}\right)$.

$C_{0}$ : Initial dye concentration $\left(\mathrm{mg} \cdot \mathrm{L}^{-1}\right)$.

$C_{e}$ : Dye concentration at equilibrium $\left(\mathrm{mg} \cdot \mathrm{L}^{-1}\right)$.

$C_{t}$ : Dye concentration at a given time $\left(\mathrm{mg} \cdot \mathrm{L}^{-1}\right)$.

$D$-R: Dubinin-Radushkevic.

$E$ : Mean free adsorption energy of dye transferred to the surface from infinity $\left(\mathrm{kJ} \cdot \mathrm{mol}^{-1}\right)$.

$h:$ Initial rate of adsorption ( $\mathrm{mol} / \mathrm{g} \mathrm{min}$ ).

$k_{1}$ : Equilibrium rate constant of pseudo-first-order sorption $\left(\mathrm{min}^{-1}\right)$.

$k_{2}$ : Equilibrium rate constant of the pseudo-second-order sorption $\left(\mathrm{g} \cdot \mathrm{mg}^{-1} \cdot \mathrm{min}^{-1}\right)$.

$k_{d}$ : Distribution coefficient ratio at different temperatures.

$k_{F}$ : Freundlich adsorption isotherm constant $\left(\mathrm{L} \cdot \mathrm{g}^{-1}\right)$.

$K_{L}$ : Langmuir adsorption isotherm constant $\left(\mathrm{L} \cdot \mathrm{mol}^{-1}\right)$.

NRK: Natural Raw Kaolinite.

$q_{e}$ : Quantity of dye adsorbed at equilibrium ( $\left.\mathrm{mg} \cdot \mathrm{g}^{-1}\right)$.

$q_{\max }:$ Maximum adsorbed quantity by the adsorbent $\left(\mathrm{mg} \cdot \mathrm{g}^{-1}\right)$.

$q_{t}$ : Quantity adsorbed at a given time $(\mathrm{mg} / \mathrm{g})$.

$R$ : Gas constant.

$T$ : Adsorption absolute temperature (K).

$V$ : Volume of dye solution (L).

$W$ : Weight of adsorbent in dye solution (g).

$\Delta G_{\text {ads }}:$ Gibbs free energy change of adsorption $\left(\mathrm{KJ} \cdot \mathrm{mol}^{-1}\right)$.

$\Delta H_{\text {ads }}$ : Enthalpy change of adsorption $\left(\mathrm{KJ} \cdot \mathrm{mol}^{-1}\right)$.

$\Delta S_{\text {ads }}$ : Entropy change of adsorption $\left(\mathrm{J} \cdot \mathrm{mol}^{-1} \cdot \mathrm{K}^{-1}\right)$.

$\varepsilon$ : Polanyi potential. 
Scientific Research Publishing (SCIRP) is one of the largest Open Access journal publishers. It is currently publishing more than 200 open access, online, peer-reviewed journals covering a wide range of academic disciplines. SCIRP serves the worldwide academic communities and contributes to the progress and application of science with its publication.

Other selected journals from SCIRP are listed as below. Submit your manuscript to us via either submit@scirp.org or Online Submission Portal.
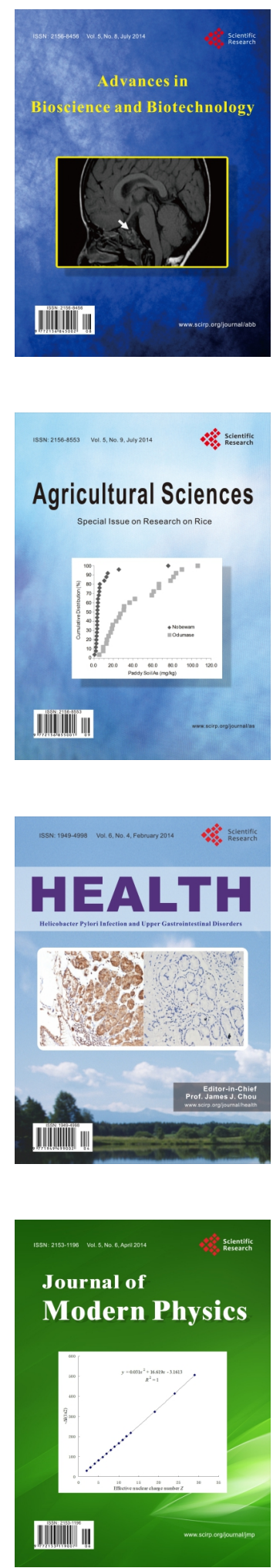
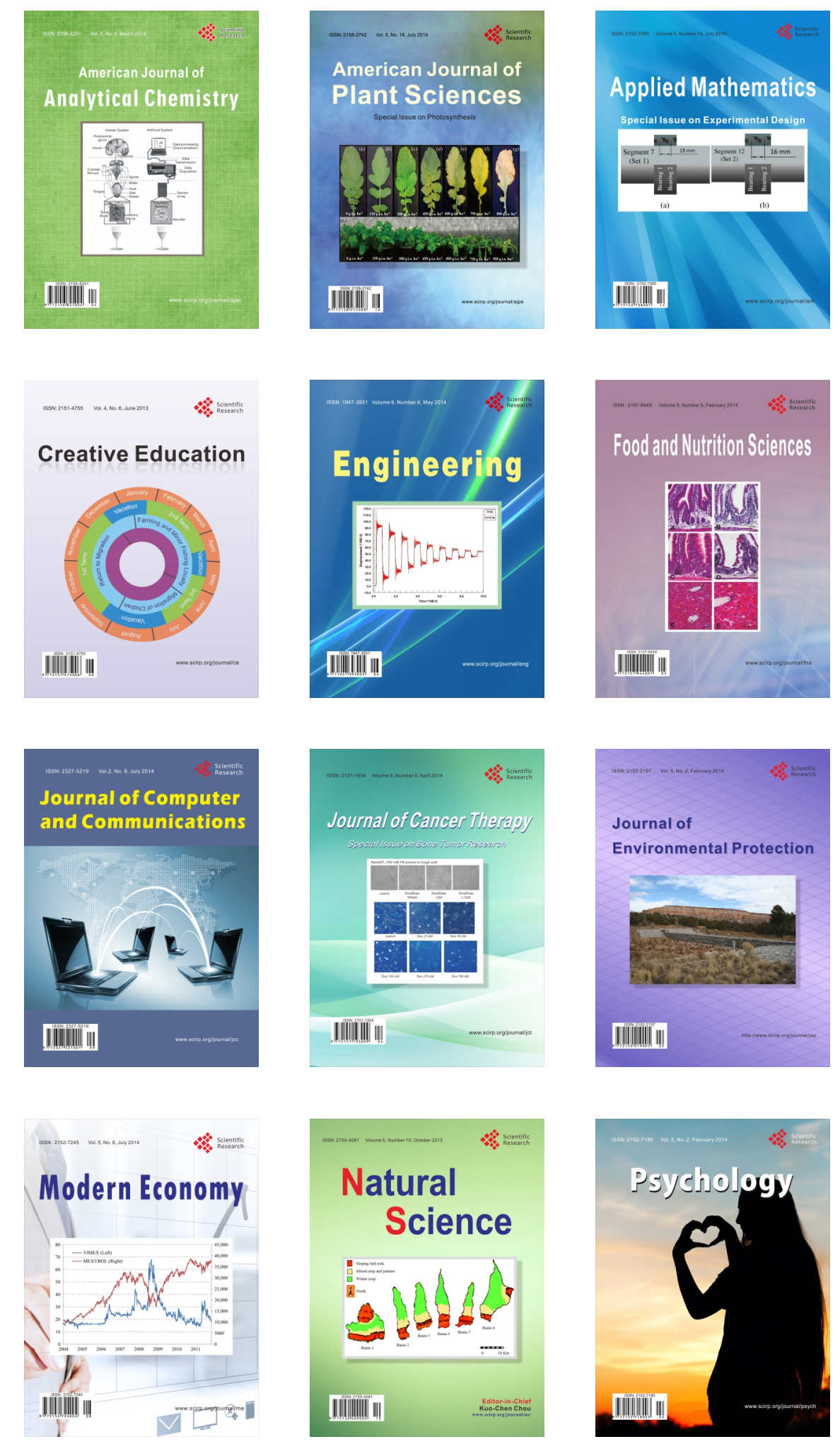